\title{
Rock lobster Jasus edwardsii larval retention by the Wairarapa Eddy off New Zealand
}

\author{
Stephen M. Chiswell*, John D. Booth \\ National Institute of Water and Atmospheric Research, PO Box 14-901, Wellington, New Zealand
}

\begin{abstract}
In February 1998, Jasus edwardsii larval catches off the east coast of New Zealand were binomial in size and stage of development. Mid-stage larvae (presumed to be from the 1997 cohort) appeared to be contained within a large permanent eddy found offshore, known as the Wairarapa Eddy. Late-stage larvae (1996 cohort) have a different distribution from the mid-stage larvae, being found closer inshore of the eddy. Pueruli (also 1996 cohort) were found well inshore of the eddy. Surface currents derived from TOPEX/Poseidon altimeter measurements of sea level are used to simulate larval concentrations. The numerical simulations show that the different distributions of the 3 groups cannot be explained on the basis of advection alone. Mid-stage concentrations appear to be well described by passive drift alone, but the simulations suggest some mechanism inducing shoreward transport is needed for both pueruli and late-stage phyllosomas. Observed puerulus concentrations are best matched by adding a shorewards-directed speed of 8 to $10 \mathrm{~cm} \mathrm{~s}^{-1}$ for between 1 and 3 wk before the date of the cruise. Late-stage phyllosoma concentrations are best matched by adding speeds of 4 to $6 \mathrm{~cm} \mathrm{~s}^{-1}$. Sustained shorewards swimming speeds of 8 to $10 \mathrm{~cm} \mathrm{~s}^{-1}$ are well within the estimates of swimming speed that have been reported elsewhere for pueruli. To our knowledge, extended directed horizontal swimming has not been reported for phyllosomas, yet in the final stage, the pleopods are almost as well developed as they are in the pueruli. These final stage larvae could well use forward pleopod propulsion, in conjunction with exopodal setai beating, to allow them to swim.
\end{abstract}

KEY WORDS: Jasus · Larval retention - Eddy · Numerical simulation · Phyllosoma · Puerulus · Rock lobster

\section{INTRODUCTION}

The red rock, or spiny, lobster Jasus edwardsii (Palinuridae) supports a valuable fishery around mainland New Zealand, with an annual catch of about $2500 t$ (Annala \& Sullivan 1998). Much of this catch comes from the east coast of the North Island (Booth 1994). This species breeds annually, with most eggs hatching in September and October. The larvae spend at least 12 , and possibly up to 24 , mo in a planktonic phyllosoma larval stage, before metamorphosing to a postlarval puerulus stage. Booth \& Stewart (1992) and (Booth 1994) suggest that after hatching near the coast the larvae develop offshore in oceanic waters before being returned to near the shelf break where they metamorphose. The phyllosoma has been thought to

\footnotetext{
•E-mail: s.chiswell@niwa.cri.nz
}

have limited ability to swim horizontally and its form is well suited to passive drift. The long life of the larval stage, coupled with its limited ability to swim, suggests that there must be sufficient recirculation between the offshore and coastal waters to prevent loss of larvae into the South Pacific Ocean.

The most likely candidate for a retentive mechanism for larvae off the south-east coast of the North Island is the Wairarapa Eddy. This eddy is formed by retroflection of the East Cape Current (ECC), which flows southwards along the east coast of the North Island. The presence of the eddy has been inferred for some time (e.g. Heath 1975), and has been well documented recently (Roemmich \& Sutton 1998). While the eddy exhibits some variability in location, its mean position as determined by an analysis of all available hydrographic data (Roemmich \& Sutton 1998) is shown in Fig. 1.

Perhaps the earliest suggestion that the Wairarapa Eddy is important in rock lobster larval retention was 
by Lesser (1978) who speculated that the large, permanent anticyclonic eddy formed where the East Cape Current turns north... could provide a mechanism for the retention of larvae...' This hypothesis is supported by Chiswell \& Roemmich (1998) who simulated larval trajectories using geostrophic surface velocities determined from TOPEX/Poseidon altimeter data. They calculated mean retention time, based on a simple definition, to be between 60 and $90 \mathrm{~d}$ outside the Wairarapa Eddy, but over $240 \mathrm{~d}$ in the centre of the eddy. Chiswell \& Roemmich (1998) suggest that once larvae get into the eddy, they have about a $40 \%$ chance of staying within it for a year or more.

Other circumstantial evidence supports the notion that the Wairarapa Eddy is the main retentive mechanism for the larvae, but a direct link has never been shown. For example, Booth \& Stewart (1992) and Booth (1994) found high phyllosoma abundance offshore in the general region of the eddy, in contrast to much lower values to the north and south. However, they did not make hydrographic measurements, and the Wairarapa Eddy can be sufficiently fragmented that it is not certain that their high counts were within the eddy.

In February 1998, a cruise was made to the ECC/Wairarapa Eddy region with the main aim of determining eddy dynamics. Hydrographic measurements were made along 5 transects radiating from the coast (Fig. 1), and plankton tows were made at most of the stations. Rock lobster catches fell into 3 classes: mid-stage phyllosomas (i.e. larvae hatched in about October 1997), late-stage phyllosomas (hatched in about October 1996), and pueruli (also hatched in about October 1996). Midstage phyllosomas were found well offshore in the Wairarapa Eddy and the pueruli were found mainly inshore, along the shelf break. These results are consistent with the idea that in the larval stage lobsters act as passive drifters, and are retained by the eddy, but that once they metamorphose into the puerulus stage, they migrate towards the coast.

More surprisingly, however, is that we found late-stage phyllosomas distributed inshore of the mid-stage phyllosomas. If there is no physical mechanism for producing such a distribution, then presumably a biological mechanism exists, suggesting the possibility that the late-stage phyllosomas have better swimming ability than previously thought, and are starting to migrate inshore prior to metamorphosis.

In this paper, after a review of the early life history of Jasus edwardsii, we present the data showing entrainment of rock lobster larvae by the Wairarapa Eddy, and the skewed distributions of the 2 developmental stages. We contrast the rock lobster larval distributions with those of the phyllosomas of a closely related slipper lobster, Scyllarus aoteanus (Scyllaridae), which also occurred in the tows. We then use surface geostrophic currents derived from TOPEX/Poseidon altimeter measurements of sea height to model passive tracer (i.e. larvae) distributions, with the intention of answering some basic questions, such as can the differences in observed distributions in phyllosomas be explained on the basis of their different time histories alone? By comparing observed distributions with simulated distributions, we make estimates of the swimming speeds pueruli need to maintain in order to traverse the western part of the ECC. We also obtain some estimates of how long it takes the Wairarapa Eddy to entrain larvae and overall loss rates.

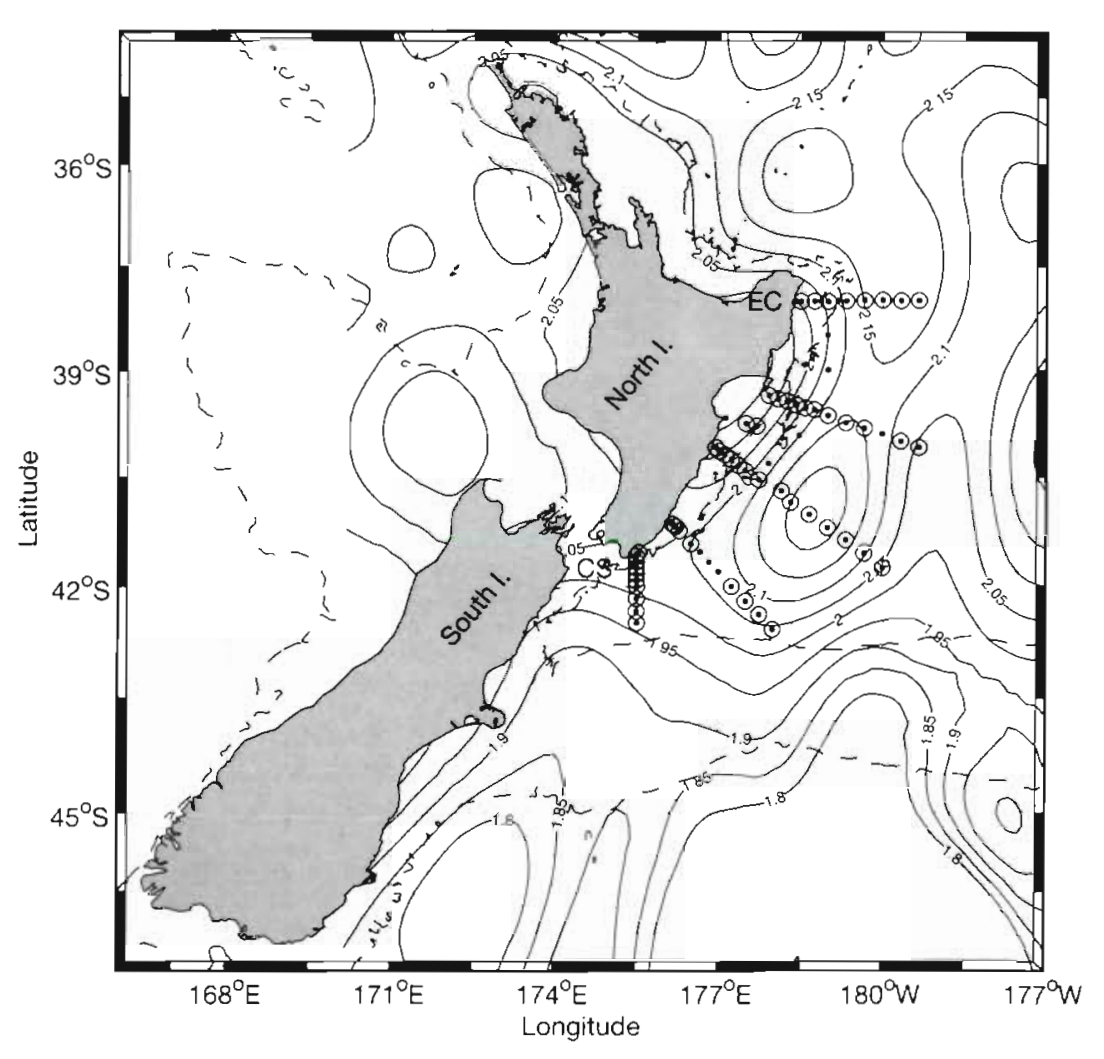

Fig. 1. Hydrographic stations and larval tows made during February 1998. Hydrographic stations are shown as $(\bullet)$, larval tows were made at circled stations (O). Also shown is contoured mean dynamic height (dyn $m$ ) from Roemmich \& Sutton (1998), and $1000 \mathrm{~m}$ isobath (dashed line). North I. = North Island, South $\mathrm{I}$. = South Island, EC = East Cape, $\mathrm{CS}=$ Cook Strait. The Wairarapa Eddy is seen as the region of closed dynamic height contours east of the North Island 


\section{ROCK LOBSTER EARLY LIFE HISTORY}

Jasus edwardsii produce 37000 to 538000 eggs, in proportion to body size (Annala \& Bycroft 1987), most of which hatch in spring (September-October). Hatching takes place inshore, often in areas of strong water flow which presumably enhances larval dispersal. There is a short-lived (few hours) pre-zoeal naupliosoma stage, followed by about 17 phyllosoma instars which have been arbitrarily divided into 11 stages (Lesser 1978). Phyllosomas (from the Greek phullon meaning leaf and soma meaning body) are transparent leaf-like plankters, whose body shape appears well suited for planktonic drifting. Phyllosoma development takes at least $12 \mathrm{mo}$, and possibly up to 24 mo (Booth \& Phillips 1994), during which time the larvae reach the final stage, which ranges in size from 35 to $50 \mathrm{~mm}$ total length (TL). The larvae then metamorphose into the puerulus stage (from the Latin puer meaning boy or child), which resembles the adult in shape and is 9 to $13 \mathrm{~mm}$ in carapace length (CL), but it is transparent. The puerulus stage is the settling stage, which may last for several weeks. Pueruli swim towards the coast until they reach shallow water, at which point they settle on the bottom and within 1 to 3 wk, depending on water temperature, moult into the juvenile stage.

Monthly levels of puerulus settlement have been measured along the major rock lobster fishing coasts of New Zealand since the 1980s (Booth 1994). In the north of the region of the ECC, the main settlement period is winter (April to September), but in the south, summer and autumn settlement (December to May) can equal or exceed the winter peak. The reasons for this geographic variation in settlement season are unknown.

Phyllosomas can be dispersed over large distances: for example, advanced phyllosomas (those Stage 5 and beyond) have been taken in large numbers near the Louisville Ridge, $1300 \mathrm{~km}$ off the North Island (Booth et al. 1998). At least recently, advanced phyllosomas have been much more abundant off the east coast of the North Island south of East Cape than off the east coast of the South Island (Booth \& Stewart 1992, Booth 1994). Booth (1994) reported that advanced phyllosomas occurred almost exclusively seaward of the continental slope while most pueruli were on the shelf.

The horizontal swimming abilities of phyllosoma larvae are not well known, with most information coming from the culture of larvae (including Jasus edwardsii) (Kittaka 1994). It has generally been presumed that phyllosomas at all stages are weak horizontal swimmers, although it is known that they can migrate quite rapidly (at least $1 \mathrm{~cm} \mathrm{~s}^{-1}$ ) vertically in the water column - phyllosomas rise to the surface at night to feed, and sink during the day to escape predation (Booth \&
Phillips 1994). Swimming of mid-and late-stage larvae often takes the form of a series of spirals in the direction in which the larva is headed (Kittaka 1994), but more directed swimming has also been observed. This ability to swim comes about through the beating of the highly setose exopods on the pereiopods.

In contrast, well-developed pleopods, with appendix internae that link opposite pairs, allow the puerulus stage to swim strongly horizontally. For example, field measurements of forward swimming speeds up to $33 \mathrm{~cm} \mathrm{~s}^{-1}$ (mean $15 \mathrm{~cm} \mathrm{~s}^{-1}$ ) have been reported in Panulirus cygnus (Phillips \& Olsen 1975), with similar speeds estimated for Jasus edwardsii (authors' unpubl. data).

Based on hatching times and previous sampling in the area (Booth 1994), larvae expected to be present in the plankton in the ECC in February 1998 are midstages from the spring 1997 hatching, and late-stages from the spring 1996 hatching.

Scyllarids have a similar life history to rock lobsters, but generally have a shorter larval life and often more coastal development (Baisre 1994). Scyllarus aoteanus (the species found in this study) is a small (up to $30 \mathrm{~mm}$ CL), infrequently encountered subtropical species, which on the east coast of New Zealand is reported only as far south as East Cape. S. aoteanus is a shallowwater $(<100 \mathrm{~m})$ species with an extended hatching period and/or variable rates of development, leading to final stage phyllosoma larvae (18 to $23 \mathrm{~mm}$ TL) being taken throughout the year (authors' unpubl. data). Based on small subtropical Scyllarus species found elsewhere, we believe phyllosoma development probably takes about $4 \mathrm{mo}$, the final stage metamorphosing to the postlarval nisto stage. Early phyllosoma stages (Stages 1 to 4 ) have been taken almost exclusively within $80 \mathrm{~km}$ of the coast, mid stages ( 5 to 7 ) in the same area but also up to $500 \mathrm{~km}$ off shore, and late stages ( 8 to 10 ) over a broad area, from inshore waters to areas more than $800 \mathrm{~km}$ from shore. Phyllosomas have been taken mainly of the east coast of the North Island, and rarely south of the Subtropical Front (in this region this front is found at about $43^{\circ} \mathrm{S}$ ).

\section{METHODS}

Hydrography. CTD: Fig. 1 shows the station locations. A Seabird CTD (conductivity-temperaturedepth) profiler in a 12-place rosette with 1.21 Niskin bottles was used to make continuous vertical profiles of temperature and salinity at each station. Water samples were collected to calibrate the conductivity sensor. CTD data collection and processing methods were the same as those detailed in Chiswell et al. (1993) and Walkington \& Chiswell (1993). 
Dynamic height, $\Delta D_{0 / 2000}$, was computed relative to 2000 dbar. We chose the lower level to be 2000 dbar principally to be consistent with previous calculations (e.g. Heath 1972a), where it was used as a level of no motion. There is other evidence to suggest that this may be a reasonable choice: Warren (1970) used the same level east of New Zealand, arguing that it lies above the deep tracer features (which are indicative of meridional flow) and in the middle of the deep oxygenminimum layer which he suggests is a region of slow horizontal velocity.

ADCP: A $150 \mathrm{kHz}$ RDI ship-mounted Acoustic Doppler Current Profiler (ADCP) was used to collect current profiles underway. The ADCP was set up to produce profiles consisting of 5 min ensembles of once-per-second pings. The nominal vertical resolution was set to $8 \mathrm{~m}$. Bottom tracking was used where possible. Navigation was derived from GPS; the latitude and longitude were recorded at the end of every 5 min ensemble.

ADCP data were processed using the CODAS system, provided by Eric Firing at the University of Hawaii.

Lobster tows. The plankton was sampled with an Engel fine-meshed (12 mm) midwater trawl. This trawl is $60 \mathrm{~m}$ long and has a nominal mouth area of $70 \mathrm{~m}^{2}$. At each station, the net was towed for $10 \mathrm{~min}$ at each of 100,60 , and $20 \mathrm{~m}$ depth horizons at about 3 knots before hauling. The contents were removed from the codend, the net checked for any enmeshed phyllosomas, and the fresh plankton sorted for phyllosomas. The mesh size meant that phyllosomas of Jasus edwardsii earlier than Stage 5, and those of Scyllarus aoteanus earlier than Stage 6, would not have been routinely retained. Phyllosomas were either frozen for protein work or fixed and preserved in $3 \%$ buffered formalin. Onshore they were measured (TL, from the anterior end of the cephalon between the eyestalks to the posterior edge of the abdomen). Previous work by Booth (1994) has shown the range in J. edwardsii larval sizes (TL) by stage in this region in January-March to be as follows: Stage 5: 7-15 mm; Stage 6: 10-19 mm; Stage 7: 14-20 mm; Stage 8: 18-25 $\mathrm{mm}_{i}$ Stage 10: 32-42; Stage 11: $37-51 \mathrm{~mm}$. (There were only 2 Stage 9 larvae caught.) These measurements formed the basis for the differentiation between the mid-stage (Stages 5 to 8 ) and the late-stage (Stages 10 to 11) phyllosomas in this study. The $S$. aoteanus larvae were dealt with in a similar manner.

Because of time constraints, larval tows were not made at a few of the hydrographic stations. At 6 stations it was not possible to sort all the plankton caught for phyllosomas. Subsampling involved sorting for larvae in at least one $20 \%$ (but usually $>50 \%$ ) aliquot of the material. The larval numbers for these stations were adjusted accordingly.
Simulations. The approach here is to use the satellite altimeter derived sea level fields to obtain surface geostrophic currents. With the current field specified in time, we model the distribution of a passive tracer using an advection scheme. This Eulerian approach is different from that in Chiswell \& Roemmich (1998), who used a Lagrangian approach to model individual larval paths.

The United States-French TOPEX/Poseidon (T/P) satellite altimeter measures sea level along the same path every $9.9156 \mathrm{~d}$ (Fu et al. 1994), and is generally reckoned to provide sea level accurate to a few $\mathrm{cm}$ (e.g. Mitchum 1994). Sea surface height derived from T/P altimetric data collected between October 1992 and March 1998 were provided to us by L.-L. Fu. These data had been mapped onto a uniform spatial grid (latitude and longitude spacing of $1 / 6^{\circ}$ ) using objective analysis techniques. They were also mapped onto an exact $10 \mathrm{~d}$ temporal sampling. For the purposes of this analysis, sea surface height from the T/P altimeter was assumed to be equivalent to dynamic height.

Because of uncertainties in the geoid, T/P data are generally considered to be variations about the true mean sea level. Here, we removed a 5 yr mean (1993-1997) from the T/P data and added the mean dynamic height $\Delta D_{0 / 2000}$ derived from an analysis of 1419 hydrographic stations (either bottle or CTD) by Roemmich \& Sutton (1998) shown in Fig. 1.

Surface zonal and meridional currents were computed from the T/P dynamic height fields assuming geostrophy:

$$
u=-\frac{10}{f} \frac{\partial}{\partial y} \Delta D \text { or } v=\frac{10}{f} \frac{\partial}{\partial x} \Delta D
$$

where $\Delta D$ is the dynamic height field obtained by adding the altimeter data to the mean dynamic height field.

The final products used here were geostrophic current fields at $1 / 6^{\circ}$ latitude and longitude resolution, every 10 days spanning the interval from October 1992 to March 1998.

The advection-diffusion of a passive tracer, $C$, can be written as:

$$
\frac{\partial C}{\partial t}=-u \frac{\partial C}{\partial x}-v \frac{\partial C}{\partial y}+K_{h} \nabla^{2} C+C_{0}
$$

where $K_{h}$ is the horizontal eddy diffusivity, and $C_{0}$ is a source function used to seed the system. Here, an initial concentration along the $1000 \mathrm{~m}$ isobath was maintained for the first month. Swimming (or transport by other means) can be simulated by adding swimming speeds to $u$ and $v$.

Implementing numerical advection schemes is generally non-trivial, and is the subject of much discussion in the literature (e.g. Pielke 1984). We used an 
upstream-forward difference scheme, whose main advantages are that it is easy to implement, unconditionally stable, and is positive definite (i.e. $C$ is never negative). The main disadvantage is that it has a high degree of computational diffusivity. The computational diffusivity depends on both speed and wavenumber of the tracer, and so cannot be expressed as a single value. To some extent, the computational diffusivity can be overcome by using higher spatial resolution and the $1 / 6^{\circ}$ grid was resampled at twice its original resolution. Numerical experiments made by measuring the dispersion of a Gaussian-shaped tracer field having scales approximately the same as the eddy indicated computational diffusivities equivalent to $K_{h}$ ranging from 100 to $300 \mathrm{~m}^{2} \mathrm{~s}^{-1}$. We believe that these may not be too unrealistic of the true values, and so did not explicitly add diffusion to our simulations.

Time steps were determined by the CFL (Courant condition), and the velocity fields were interpolated between the $10 \mathrm{~d}$ fields.

\section{RESULTS}

\section{Hydrography in February 1998}

Fig. 2 shows surface dynamic height anomaly, $\Delta D_{0 / 2000}$, from the CTD stations mapped using objective analysis methods. The spacing of the transects determines the resolution of the mapped field; a decorrelation length scale of 1 degree in each direction was used. Velocity vectors averaged surface to $40 \mathrm{~m}$ from the ADCP are superimposed.

The 2 regions of high dynamic height indicate the Wairarapa Eddy was not in its mean position as given by Roemmich \& Sutton (1998). Instead there is a small eddy centred about $177^{\circ} \mathrm{E}, 42^{\circ} \mathrm{S}$, and a larger lobe of anticyclonic circulation centred about $180^{\circ} \mathrm{E}, 40^{\circ} \mathrm{S}$. Although the 2 northern transects extended beyond the maximum in dynamic height, they were far enough apart at their offshore ends that one cannot interpolate between them and the structure of the dynamic height field is uncertain.

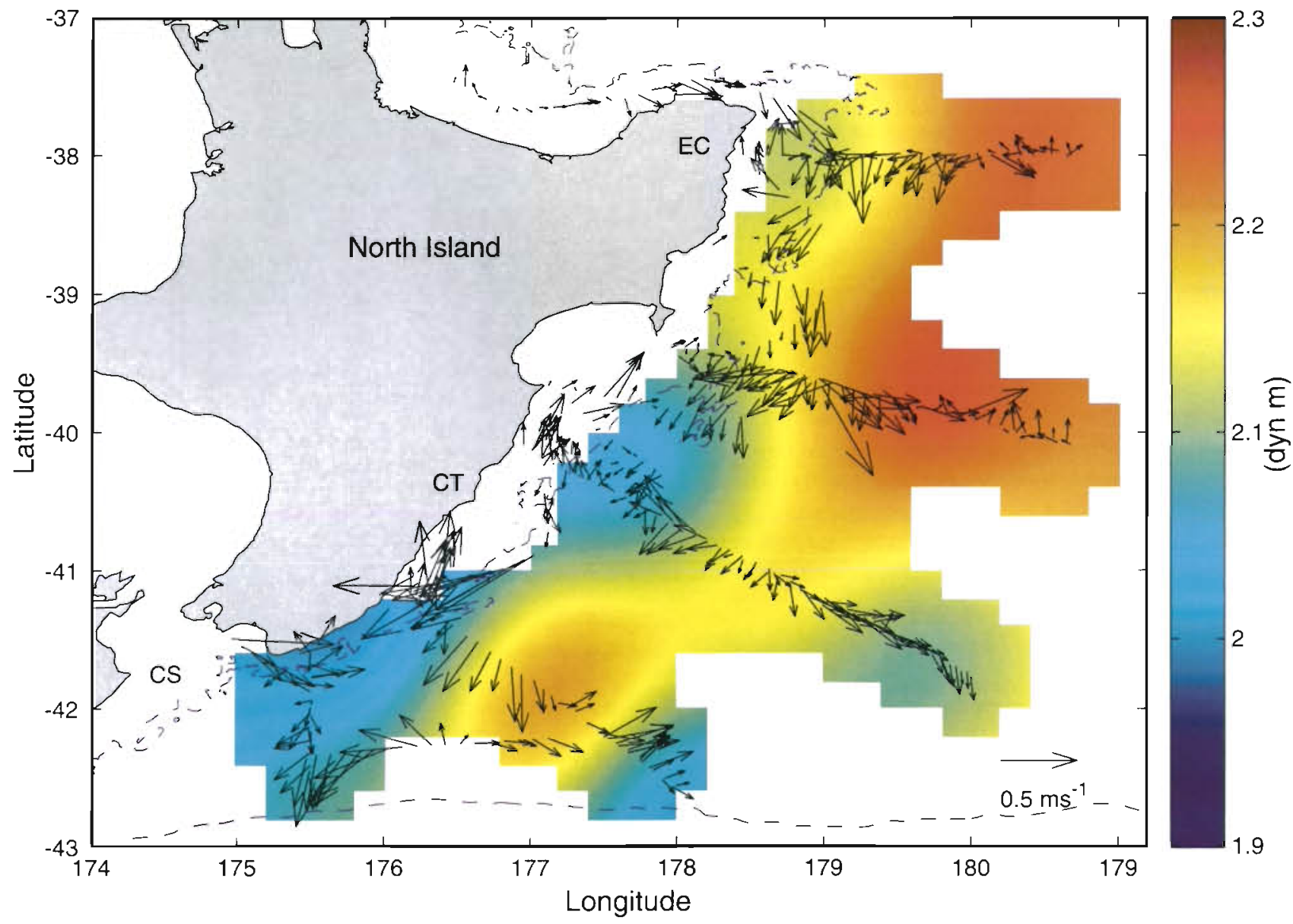

Fig. 2. Mean dynamic height, $\Delta D_{0 / 2000}$ (dyn $\mathrm{m}$ ), obtained from objective analysis of station data (see text). Superimposed are velocity vectors $(0$ to $40 \mathrm{~m})$ from shipboard acoustic Doppler current profiler $(A D C P) . E C=E a s t C a p e, C S=C o o k$ Strait, $C T=$ Cape Turnagain. Dashed line is $1000 \mathrm{~m}$ isobath 
Although there is considerable variability in the ADCP measurements, presumably caused by tides and processes such as inertial oscillations, there is a broad agreement between the current vectors and the dynamic height field (Fig. 2). One can see, for example, the ECC flowing south along the inshore slope in dynamic height, and anticyclonic circulation around the smaller eddy. Both the dynamic height field and ADCP measurements hint at a narrow northward coastal current (although because of the $1^{\circ}$ length scale used in the objective analysis, much of the detail of the dynamic height field is lost in this plot). This northward flow is also seen in current meters deployed along the Wairarapa coast (unpubl. data), has been documented previously (Heath 1975), and is known variously as the Southland Current extension or the Canterbury Current.

\section{Lobster catches}

Tow catches of Jasus edwardsii fell into 3 classes:

(1) Mid-stage phyllosomas. They were Stage 5-8 larvae, 7 to $25 \mathrm{~mm}$ TLi these would have hatched about October 1997

(2) Late-stage phyllosomas. They were Stage 10-11 larvae, 32 to $51 \mathrm{~mm} \mathrm{TL}$; these would have hatched about October 1996.

(3) Pueruli; these are postlarval lobsters recently metamorphosed from final-stage phyllosomas; these also would have hatched about October 1996.

Detailed breakdown of the tow catches is given in Table 1. This table also gives the catches of Scyllarus aoteanus phyllosomas. Catches for all 4 classes are plotted in Fig. 3, superimposed on dynamic height, as dots, with the area of the dots proportional to the size of the catch. Catches are also shown plotted as a function of station offshore in Fig. 4.

A total of 1146 (corrected to take into account the subsampling) mid-stage phyllosomas was collected. Fig. 3 shows the spatial distribution of the catches. Visually, the mid-stage larvae seem to be well correlated with the dynamic height-relatively few larvae were collected outside of the eddy. When plotted against dynamic height (Fig. 5), catches remain less than 30 per trawl (cpt) for dynamic height less than about 2.14 dyn m, but rise as high as $140 \mathrm{cpt}$ for higher values of dynamic height. The plot suggests a polynomial fit, and we obtained a correlation-squared coefficient $\left(\mathrm{r}^{2}\right)$ of 0.62 for a quadratic fit.

A corrected total of 1565 late-stage phyllosomas was collected (Fig. 3). Compared with the younger midstages, the distributions appear to be closer inshore. The distributions also appear to extend further south, for example, 40 late-stage phyllosoma were found on
Table 1 Jasus edwardsii, Scyllarus aoteanus. Corrected lobster tow catches. Stations are numbered from inshore along each transect

\begin{tabular}{|c|c|c|c|c|}
\hline \multirow[t]{2}{*}{ Stn } & \multicolumn{3}{|c|}{ Jasus edwardsii } & \multirow{2}{*}{$\begin{array}{c}\text { Scyllarus aoteanus } \\
\text { Late-stage }\end{array}$} \\
\hline & Mid-stage & Late-stage & Pueruli & \\
\hline $1-2$ & 0 & 0 & 0 & 0 \\
\hline $1-3$ & 4 & 6 & 6 & 10 \\
\hline $1-5$ & 18 & 127 & 4 & 15 \\
\hline $1-7$ & 61 & 98 & 13 & 4 \\
\hline $1-8$ & 47 & 82 & 7 & 22 \\
\hline 1.9 & 91 & 53 & 7 & 169 \\
\hline $1-10$ & 46 & 7 & 1 & 57 \\
\hline $1-11$ & 18 & 101 & 4 & 17 \\
\hline $2-1$ & 0 & 0 & 0 & 0 \\
\hline $2-2$ & 2 & 1 & 3 & 0 \\
\hline $2-3$ & 0 & 12 & 20 & 15 \\
\hline $2-4$ & 6 & 156 & 32 & 48 \\
\hline $2-5$ & 14 & 320 & 28 & 51 \\
\hline $2-6$ & 101 & 33 & 3 & 21 \\
\hline $2-7$ & 130 & 26 & 3 & 13 \\
\hline $2-8$ & 107 & 12 & 0 & 9 \\
\hline $2-9$ & 126 & 23 & 6 & 15 \\
\hline $2-11$ & 42 & 23 & 2 & 17 \\
\hline $2-12$ & 66 & 15 & 3 & 19 \\
\hline $2 a-1$ & 0 & 0 & 4 & 0 \\
\hline $2 a-2$ & 1 & 1 & 2 & 0 \\
\hline $3-1$ & 0 & 0 & 0 & 0 \\
\hline $3-2$ & 1 & 0 & 17 & 0 \\
\hline $3-3$ & 3 & 12 & 9 & 3 \\
\hline $3-4$ & 2 & 15 & 12 & 1 \\
\hline $3-5$ & 8 & 87 & 23 & 6 \\
\hline $3-6$ & 0 & 0 & 5 & 0 \\
\hline $3-7$ & 8 & 40 & 20 & 3 \\
\hline $3-8$ & 12 & 38 & 16 & 35 \\
\hline $3-9$ & 12 & 36 & 6 & 13 \\
\hline $3-10$ & 54 & 13 & 3 & 20 \\
\hline $3-11$ & 27 & 62 & 12 & 0 \\
\hline $3-12$ & 14 & 12 & 2 & 0 \\
\hline $3-13$ & 19 & 35 & 3 & 1 \\
\hline $3-14$ & 18 & 24 & 0 & 3 \\
\hline $4-2$ & 0 & 0 & 14 & 0 \\
\hline $4-3$ & 0 & 0 & 13 & 0 \\
\hline $4-4$ & 1 & 12 & 22 & 0 \\
\hline $4-5$ & 2 & 10 & 9 & 0 \\
\hline $4-9$ & 53 & 14 & 7 & 0 \\
\hline $4-10$ & 22 & 12 & 3 & 0 \\
\hline $4-11$ & 5 & 7 & 3 & 0 \\
\hline $4-12$ & 0 & 0 & 2 & 0 \\
\hline $5-1$ & 2 & 19 & 3 & 0 \\
\hline $5-2$ & 3 & 7 & 4 & 0 \\
\hline $5-3$ & 0 & 10 & 2 & 0 \\
\hline $5-4$ & 0 & 1 & 2 & 0 \\
\hline $5-5$ & 0 & 1 & 1 & 0 \\
\hline $5-6$ & 0 & 2 & 3 & 0 \\
\hline $5-7$ & 0 & 0 & 2 & 0 \\
\hline $5-8$ & 0 & 0 & 0 & 0 \\
\hline $5-9$ & 0 & 0 & 6 & 0 \\
\hline $5-10$ & 0 & 0 & 11 & 0 \\
\hline Total & 1.146 & 1565 & 383 & 587 \\
\hline
\end{tabular}



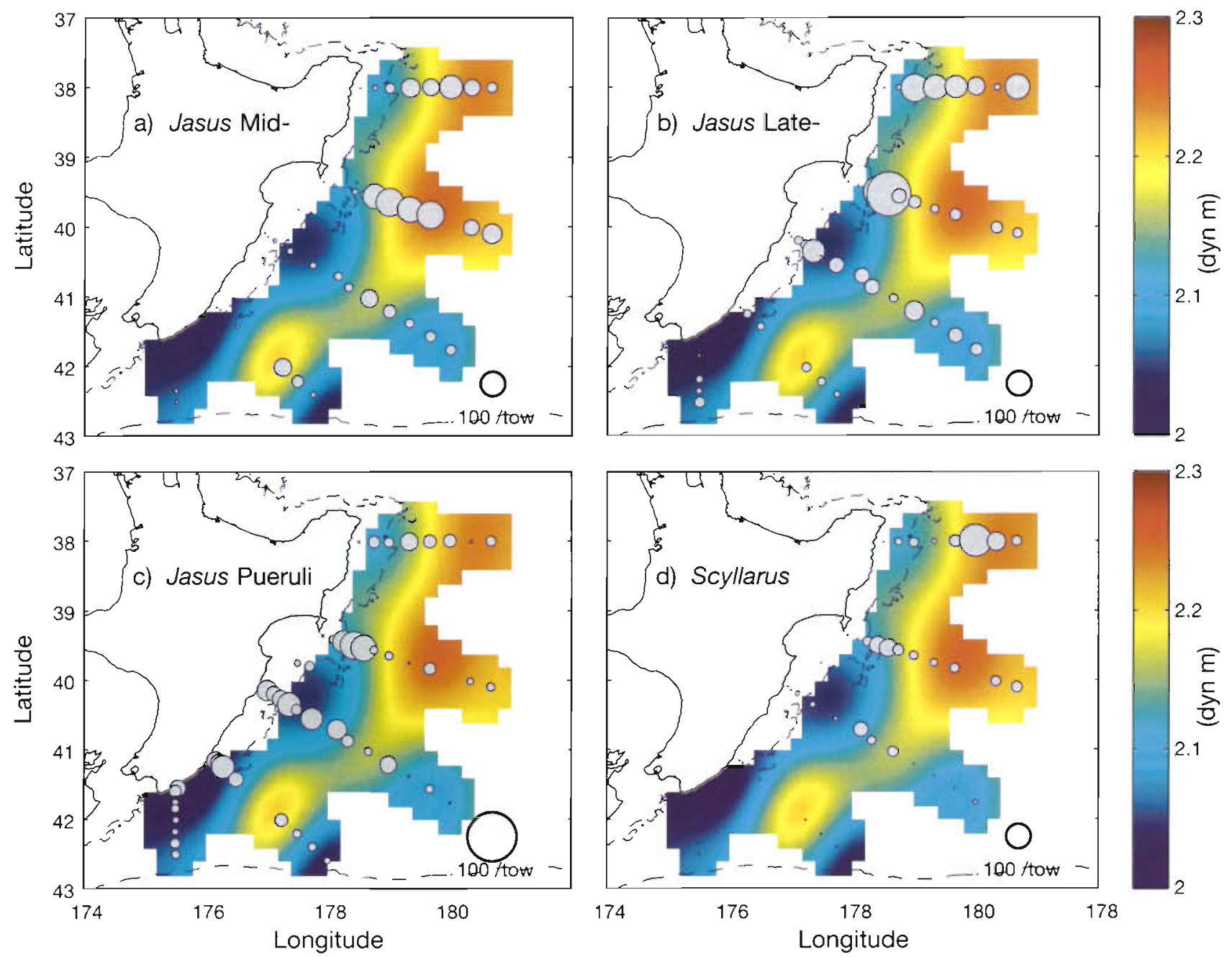

Fig. 3. Plankton trawl catches (lobsters per tow) superimposed on dynamic height (dyn $\mathrm{m}$ ). The areas of plotted circles are proportional to number of lobsters caught per half-hour trawl (note the scale is not the same for all panels). Dashed line is $1000 \mathrm{~m}$ isobath. (a) Jasus edwardsii mid-stage phyllosomas; (b) J. edwardsii late-stage phyllosomas; (c) J. edwardsii pueruli; and (d) Scyllarus aoteanus late-stage phyllosomas

Transect 5, compared to 5 mid-stage. When plotted against dynamic height, highest catches occurred at dynamic heights of 2.2 dyn $\mathrm{m}$, and tailed off at higher dynamic height. Correlation-squared for a quadratic fit is 0.16 .

A corrected total of 383 pueruli was collected, and their distribution is also shown in Fig. 3. Compared to both phyllosoma groups, they appear to be found well inshore. There is no relationship between catch and dynamic height, with correlation-squared values for linear and quadratic fits near 0 .

It is tempting from Figs $3 \& 4$ to claim that midstage phyllosomas are found within the eddy, that the pueruli are found inshore, and that the late-stage phyllosomas are found somewhere in between. This is consistent with the notion that the mid-stage phyllo- soma behave as passive drifters, and that pueruli actively swim towards the coast. However, such a distribution for the late-stage larvae raises the question why are they found closer inshore-is there a physical reason for this, or do the phyllosomas employ some strategy to take them inshore?

Before addressing these questions, we need to determine whether the late-stage phyllosomas have different distributions. Bootstrap tests (see 'Appendix 1') confirm that there are statistically distinguishable differences between the larval distributions of all classes. We note that 1 large catch in Transect 2, which had counts nearly double the next closest one and visually biases the impression of late-stage larvae being found further inshore, does not affect the statistical significance of the distribution. 

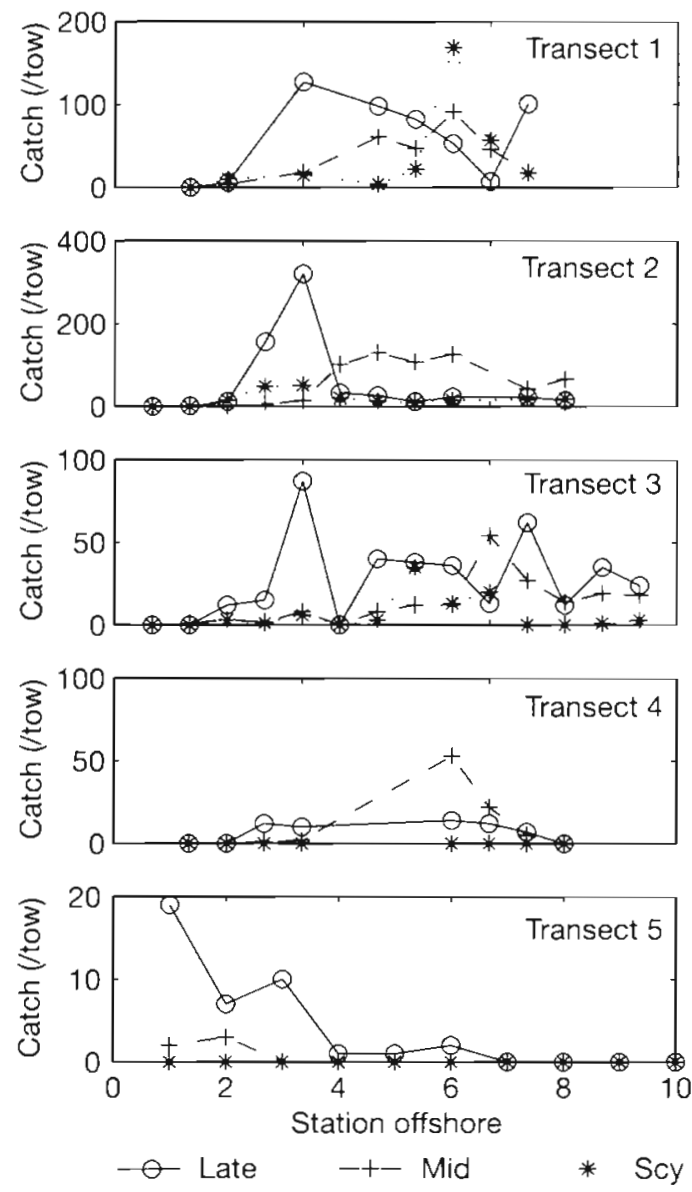

Fig. 4. Plankton trawl catches (lobsters per tow) plotted as a function of CTD cast offshore for each transect, northernmost transect is Transect 1. Late = late-stage Jasus edwardsii phyllosomas, Mid = mid-stage $J$. edwardsii phyllosomas, Scy $=$ Scyllarus aoteanus late-stage phyllosomas

A corrected total of 587 phyllosomas of Scyllarus aoteanus were caught. In contrast to Jasus edwardsii, the larvae of $S$. aoteanus were all Stages 7 to 10 and appeared to form just 1 cohort. Most were Stage $8(21 \%)$, Stage $9(45 \%)$, or Stage $10(32 \%)$, with no hint of different distribution with stage of development. S. aoteanus were most abundant in the north and were absent along the 2 southern transects (Fig. 3). On the northernmost transect, high abundance was associated with high dynamic height in a similar manner to the mid-stage Jasus edwardsii phyllosomas. On the next 2 transects, the abundance was lower and the larvae more widespread.

\section{Tracer simulations}

Validation of T/P derived geostrophic currents both in the New Zealand region, and globally, has been treated elsewhere, and is not discussed here. For example, Chiswell \& Roemmich (1998) showed good agreement between currents measured off East Cape with those derived from the T/P data.

Fig. 6 shows the results of a simulation of the 1996 year cohort. This simulation was started from 1 October 1996, and run through to 22 February 1998 (the approximate mid-point of the cruise). Initially, tracer was seeded along the $1000 \mathrm{~m}$ isobath from about $36^{\circ} \mathrm{S}$ to $41^{\circ} \mathrm{S}$. This source of tracer was maintained for $1 \mathrm{mo}$ to simulate presumed larval hatching, and then turned off. (In reality, hatching occurs closer to the coast, starts earlier in the north and progresses south.) Details of how larvae get offshore are not investigated here, we simply make the assumption that larvae move from the coastal zone to offshore. Fig. 6 shows simulated tracer concentrations at $0,1,2,3,4$ mo after initialisation and at 22 February 1998. Dynamic height from the T/P is shown as contours, and derived velocities are superimposed on the tracer concentration in each case.

One month after the start of the simulation (Fig. 6b), streamers of tracer have begun to encircle the Wairarapa Eddy, but it takes some time for the tracer to be fully entrained into the eddy, which in this simulation
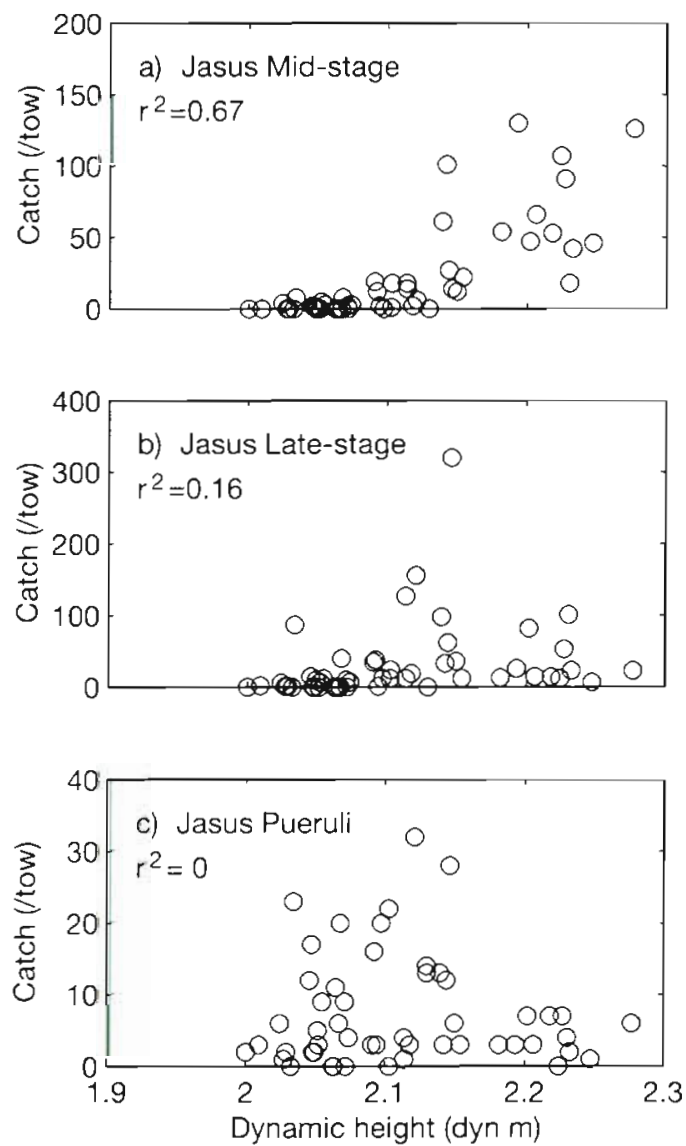

Fig. 5. Plankton trawl catches (lobsters per tow) as a function of dynamic height (dyn $\mathrm{m}$ ). (a) Jasus edwardsii mid-stage phyllosomas; (b) J. edwardsui late-stage phyllosomas; and (c) J. edwardsii pueruli 

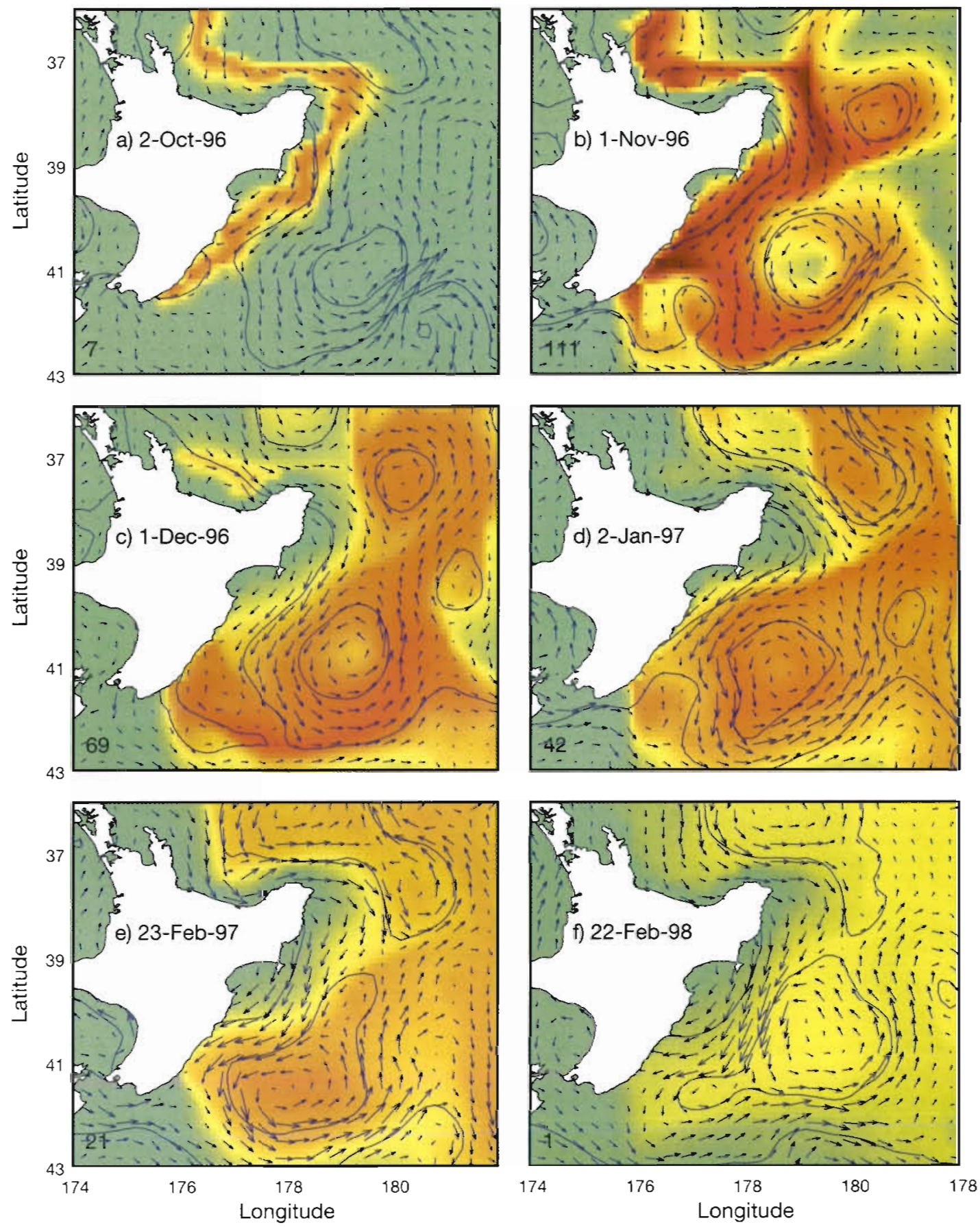

Fig. 6. Passive tracer concentrations (arbitrary units) from the numerical simulations. Concentration on 2 October 1996 (a) shows the source distribution (this source is maintained for $1 \mathrm{mo}$ ), the following panels show tracer at denoted times. Contours of dynamic height (dyn $\mathrm{m})$, and vectors of surface geostrophic current $\left(\mathrm{m} \mathrm{s}^{-1}\right)$ derived from the T/P data are superimposed

appears to have occurred by about 3 mo (Fig. 6d). At the time of the cruise in February 1998, concentration is more or less co-located with dynamic height.

A similar simulation was made for the 1997 cohort, using the same initial conditions (but starting 1 yr later in 1 October 1997). The final (i.e. 22 February 1998) tracer concentrations for the October 1997 and October 1996 cohorts are shown in Fig. 7a,b (note that the colour scales are different in these plots). Mid- and late-stage phyllosoma catches are superimposed on the respective plots. It is clear from the figure that the simulated tracer concentrations have substantially the 

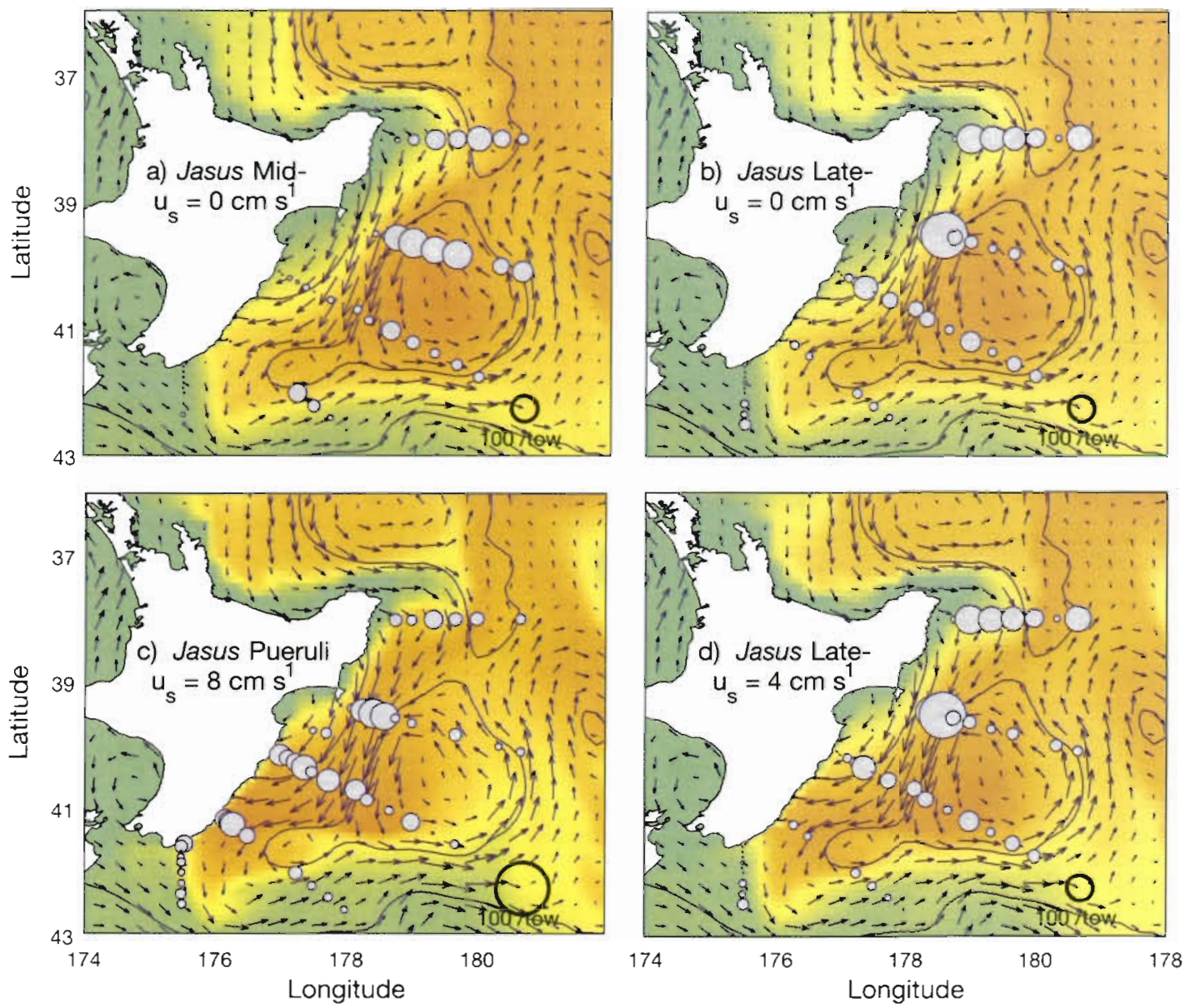

Fig. 7. Best-fit simulated tracer concentrations (arbitrary units) for 22 February 1998, allowing shorewards-directed swimming (see text and Table 2). Observed Jasus edwardsii catches are superimposed. (a) For mid-stage phyllosomas, assuming hatching in October 1997, and no swimming ability; (b) for late-stage phyllosomas, assuming hatching in October 1996, and no swimming ability; (c) for pueruli, assuming hatching in October 1996, and swimming speed of $8 \mathrm{~cm} \mathrm{~s}^{-1}$ from 4 February 1998; and (d) for late-stage phyllosomas, assuming hatching in October 1996, and swimming speed of $4 \mathrm{~cm} \mathrm{~s}^{-1}$ from 4 February 1998 . Contours of

dynamic height (dyn $\mathrm{m}$ ), and vectors of surface geostrophic current $\left(\mathrm{m} \mathrm{s}^{-1}\right)$ derived from the T/P data are superimposed

same spatial distributions and mimic the 22 February dynamic height field. This implies that the tracer patterns are sensitive only to the history of the velocity field on time scales much shorter than a year. There is a reasonable correspondence between simulated and observed concentrations for mid-stage phyllosomas, but the late-stage phyllosomas are found inshore of the simulated field.

Because we later compare observed catch data with simulated tracer concentrations, we note that the dynamic height determined from T/P for 22 February 1998 shows the general features of the observed dynamic height field, in particular, the small anticyclonic eddy at $177^{\circ} \mathrm{E}, 42^{\circ} \mathrm{S}$ is resolved. However, the main body of the Wairarapa Eddy appears to be farther to the south in the T/P data than in the hydrography.

We can make some estimate of the retention efficiency of the Wairarapa Eddy by summing the trapped concentration for February 1998 and comparing it to the total amount released. Most of the released tracer is lost early - about $80 \%$ in the first 4 mo. About $1 \%$ of the total tracer released is retained in the eddy on 22 February 1998. This retention efficiency is quite sensitive to release location. For example, tracer released too far south tends to get advected away before entrainment, and tracer released too far north tends to get entrained in an eddy north of the Wairarapa Eddy (this is the East Cape Eddy of Roemmich \& Sutton 1998)

\section{Swimming speed estimates}

Swimming ability, or more precisely, onshore-transport speeds within each group (mid-, late-, puerulus) can be estimated by introducing a shorewards directed 

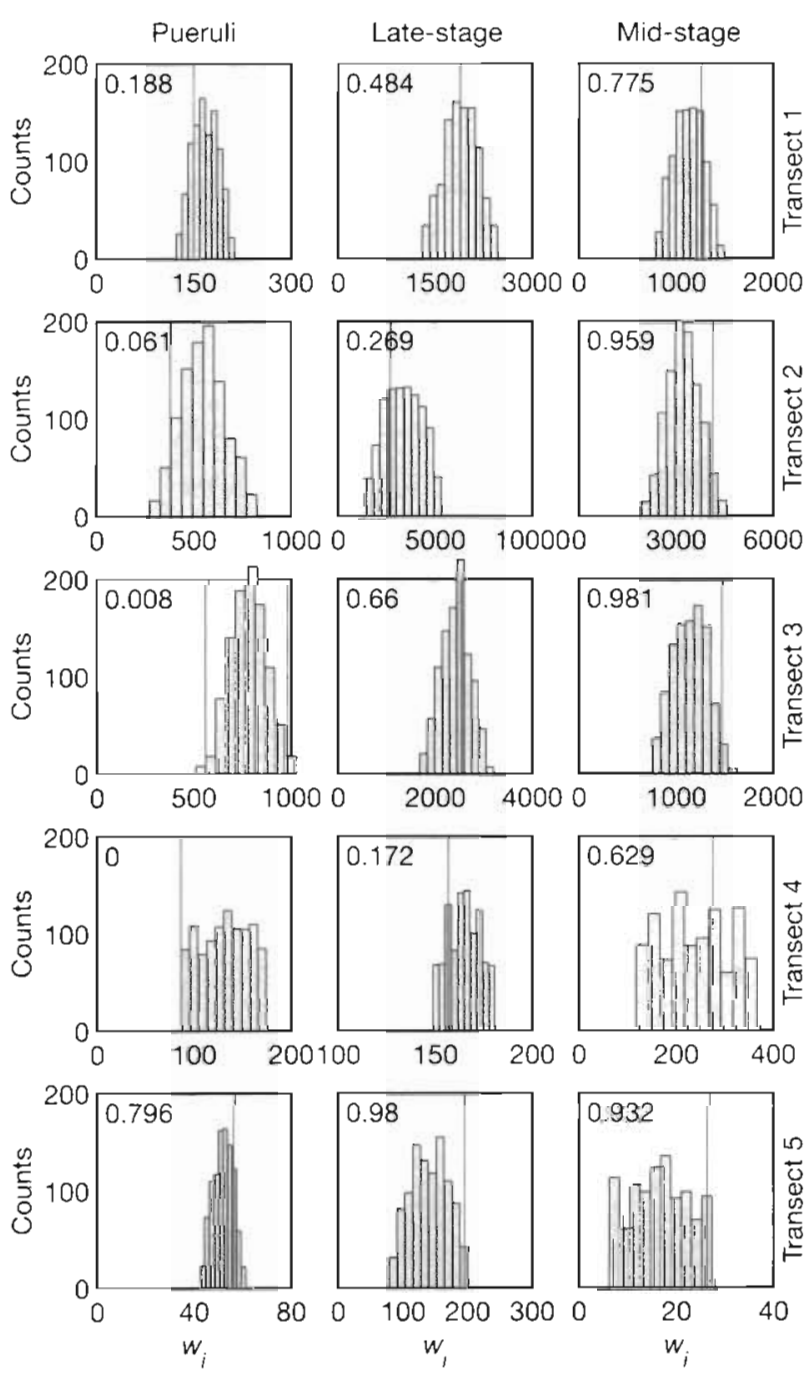

Fig. 8. Distributions of weighted catch position (see 'Appendix 1') for the 3 Jasus groups as a function of transect. Distributions show weights from Monte-Carlo simulations of randomly reordered catches. Vertical lines show observed weights. Numbers in each panel show proportion of randomly-distributed weights that fall below observed values

transport speed into the simulations and determining speeds necessary to produce tracer concentrations that best match the observed catch distributions. This was done by allowing the tracer to drift passively until some arbitrary time before 22 February 1998 , and then introducing a swimming component directed towards the coast. Because little is known in detail about when the transitions are made from one stage to the next, 3 swimming durations were used: 8,16 and $24 \mathrm{~d}$. For each duration, runs with 6 swimming speeds were made, and the final simulated concentrations (i.e. on 22 February 1998) were compared with the observed catches for each group. The test of fit used here was simply to compute the correlation coefficient between observed catch rates and simulated concentrations at the sample stations. Data from Transect 1 were dropped from this analysis because, as noted above, T/P derived eddy location is further south than observed. These correlations are shown in Table 2.

For the mid-stage phyllosomas, best fits for all 3 swimming durations were for zero swimming speed, which is consistent with the premise that these phyllosomas have no horizontal swimming ability.

For the late-stage phyllosomas, best fit between observed catches and simulated tracer occurs for swimming speeds of about 4 to $6 \mathrm{~cm} \mathrm{~s}^{-1}$, depending on the duration. For the pueruli, best fit occurs for swimming speeds of about 8 to $10 \mathrm{~cm} \mathrm{~s}^{-1}$.

Fig. $7 \mathrm{c}, \mathrm{d}$ shows the best-fits for $16 \mathrm{~d}$ swimming durations $\left(8 \mathrm{~cm} \mathrm{~s}^{-1}\right.$ for pueruli and $4 \mathrm{~cm} \mathrm{~s}^{-1}$ for late-stage phyllosoma). As might be expected, the main effect of introducing a swimming speed is to move the tracer concentrations inshore and (because of the ECC) to the south of the eddy centre. The superimposed larval catches show this is precisely what happens to the larvae. Relative to the eddy location, the puerulus, and to some extent, the late-stage phyllosoma catches were skewed both inshore and to the south. For example, the southern-most transect accounted for $9 \%$ of the total puerulus catch, $3 \%$ of the late-stage catch, but only $0.4 \%$ of the mid-stage catch.

While it is optimistic to expect simple simulations such as these to accurately predict observed distributions, there are several features worth noting. The minimum swimming speed for pueruli is set by the fact that they need to cross the ECC from the eddy and make it to the coast before being swept to the south. Mean current speeds within the ECC are about $25 \mathrm{~cm}$ $\mathrm{s}^{-1}$, so that it takes about $20 \mathrm{~d}$ for water to flow from the northern edge of the eddy to Cook Strait. The eddy is about $150 \mathrm{~km}$ off shore, leading to a minimum swimming speed of about $9 \mathrm{~cm} \mathrm{~s}^{-1}$. This is consistent with the speed estimated above.

Table 2. Correlation coefficients for observed catches and simulated tracer concentrations for various numerical simulations. All simulations assume no swimming speed until prescribed days before 22 February 1998. Underlined values are highest correlations for given swimming speed

\begin{tabular}{|c|c|c|c|c|c|c|c|}
\hline \multirow{2}{*}{\multicolumn{2}{|c|}{$\begin{array}{l}\text { Swimming } \\
\text { time }\end{array}$}} & \multicolumn{6}{|c|}{ Speed $\left(\mathrm{cm} \mathrm{s}^{-1}\right)$} \\
\hline & & 0 & 2 & 4 & 6 & 8 & 10 \\
\hline \multirow[t]{3}{*}{$8 d$} & Pueruli & -0.03 & 0.10 & 0.24 & 0.37 & 0.45 & 0.53 \\
\hline & Late-stage & 0.20 & 0.27 & 0.32 & 0.35 & 0.35 & 0.32 \\
\hline & Mid-stage & $\underline{0.73}$ & 0.68 & 0.59 & 0.49 & 0.37 & 0.24 \\
\hline \multirow[t]{3}{*}{$16 \mathrm{~d}$} & Pueruli & -0.03 & 0.16 & 0.35 & 0.50 & 0.57 & 0.56 \\
\hline & Late-stage & 0.20 & 0.27 & $\underline{0.28}$ & 0.26 & 0.21 & 0.14 \\
\hline & Mid-stage & $\underline{0.73}$ & 0.59 & 0.41 & 0.23 & 0.05 & -0.10 \\
\hline \multirow[t]{3}{*}{$24 \mathrm{~d}$} & Pueruli & -0.03 & 0.19 & 0.39 & 0.53 & $\underline{0.58}$ & 0.52 \\
\hline & Late-stage & 0.20 & 0.25 & 0.26 & 0.24 & $\overline{0.17}$ & 0.08 \\
\hline & Mid-stage & 0.73 & 0.52 & 0.31 & 0.12 & -0.06 & -0.22 \\
\hline
\end{tabular}




\section{DISCUSSION}

The main findings of this work are that in February 1998, Jasus edwardsij larval catches were binomial in size and stage of development, and that the groups were differently distributed across the ECC/Wairarapa Eddy region. There were mid-and late-stages present, but the late-stages comprised only the penultimate and final stages. This was the general pattern seen too in previous sampling at this time of the year in this area, in 1980-81, 1988, and 1994-95 (authors' unpubl. data). We assume that the mid-stage phyllosomas were about 4 mo old (i.e. hatched September-October 1997), and that the late-stage phyllosomas and pueruli were about 16 mo old (hatched in 1996), although we cannot dismiss the possibility that the late-stage phyllosomas and pueruli were from the 1995 hatching. Mid-stage phyllosomas appeared correlated with dynamic height, while pueruli were mainly found well inshore. Latestage phyllosomas appeared to have a statistically distinguishable different distribution from the mid-stages, also being found closer inshore.

We believe the Scyllarus aoteanus larvae to be about the same age as the mid-stage rock lobster phyllosomas, yet they had somewhat different spatial patterns. This probably reflects the different larval strategies of these 2 lobsters (Baisre 1994) in a way we do not fully understand. Adult $S$, aoteanus have only been reported north of East Cape, so it is not surprising to find most larvae on the northernmost transects.

These observations, together with the numerical simulations, have strengthened the conclusions of Chiswell \& Roemmich (1998) and earlier workers (e.g. Lesser 1978, Booth \& Stewart 1992), and make a compelling case that not only are rock lobster larvae trapped in the Wairarapa Eddy, but this trapping is necessary to maintain the rock lobster population. This is not the only case where larval development is thought to take place in eddies with similar retention times (Lee et al. 1994, Polovina \& Moffitt 1995).

The numerical simulations have also shown that the different distributions of the 3 groups cannot be explained on the basis of their different time histories by advection alone, but suggest some mechanism inducing shoreward transport is needed for both pueruli and late-stage phyllosomas. Pueruli are known to be good swimmers, and a sustained shorewards swimming speed of 8 to $10 \mathrm{~cm} \mathrm{~s}^{-1}$ is well within the estimates of swimming speed of 6 to $46 \mathrm{~cm} \mathrm{~s}^{-1}$ that have been reported elsewhere (Phillips \& Olsen 1975, Lyons 1980, Macmillan et al. 1992). To our knowledge, extended directed horizontal swimming has not been reported for phyllosomas, yet in the final stage (Stage 11), the pleopods are externally almost as well developed, with appendix internae, as they are in the pueruli. In conjunction with exopodal setal beating, these final stage larvae could well use forward pleopod propulsion to allow them to swim. Minimal mean ascent rates for mid- and late-stage Jasus edwardsii larvae have been estimated to be about $1 \mathrm{~cm} \mathrm{~s}^{-1}$, and Stage 5 phyllosomas have been observed to swim horizontally in tanks at about $2 \mathrm{~cm} \mathrm{~s}^{-1}$ (authors' unpubl. data); sustained speeds of 4 to $6 \mathrm{~cm} \mathrm{~s}^{-1}$ for the final stage therefore seem possible.

It is not well established what navigation methods are used by pueruli in their migration to the coast. But if late-stage larvae are also attempting to make such a migration, then they must possess at least a rudimentary form of the same method. One commonly quoted theory (Phillips \& Macmillan 1987) is that pueruli use vibrational cues, and sense underwater sound emanating from the coast. The sensory system in the latestage phyllosoma of Jasus edwardsii is not as well developed as it is in the puerulus (Nishida \& Kittaka 1992, Jeffs et al. 1997), but 7 types of integumental organs, including mechanoreceptors, have been described for it.

If the late-stage phyllosomas are not actively swimming, then there must be some mechanism that differentially advects late-stage phyllosomas inshore compared to the mid-stage larvae. With the predominant westerly and south-westerly winds, Ekman transport is to the north and north-west. Ekman transport alone would not be expected to lead to differential distributions, but when combined with different vertical distributions, it might. For example, if late-stage phyllosoma were to stay higher in the water column than the midstage (i.e in the Ekman layer), they could be transported differentially towards the coast. Taking a wind speed of $15 \mathrm{~m} \mathrm{~s}^{-1}$, the Ekman volume transport $(Q=\tau / f$. where $\tau=$ the wind stress; $f=$ Coriolis parameter) (e.g. Pond \& Pickard 1978) is about $3.5 \mathrm{~m}^{2} \mathrm{~s}^{-1}$. If this transport is distributed over $100 \mathrm{~m}$, the Ekman-induced speeds are about $3.5 \mathrm{~cm} \mathrm{~s}^{-1}$. This is about the speed required from our simulations, but for this mechanism to work with this wind speed, late-stage and mid-stage phyllosomas would have to be continuously separated vertically, and this is not the case (they were caught in the same tows). Stronger winds acting for less time (the Ekman transport is approximately proportional to wind-speed squared) may provide the needed transport.

Different vertical distributions of mid-and late-stage phyllosomas are thought to be important in shoreward transport of Panulirus cygnus off Western Australia (Phillips 1981), but there is not the same detailed information on depth distributions for Jasus edwardsii to indicate whether this mechanism is involved here.

Late-stage phyllosomas and pueruli are almost certainly from the same year class, and it is surprising that 
the total catch in this year class is larger than that of mid-stage larvae (1948 vs 1146). Even if the highest late-stage catch is excluded, there are still more latestage plus pueruli than mid-stage phyllosomas. Presumably, the main reason for this is that the mesh size $(12 \mathrm{~mm})$ of the net allowed a significant number of the mid-stage larvae to escape. It could also be that the larval release in 1996 was much higher than in 1997. We cannot differentiate between these 2 possibilities, but note that if mortality is high, then either our sampling has to be extremely biased, or there has to be large interannual variability.

The approach used here is simplistic in several respects beyond the limitations of $\mathrm{T} / \mathrm{P}$ ability to measure sea level. Assuming that plankton distributions can be derived from surface velocities makes the implicit assumption that there is little baroclinic structure to the circulation. In fact, while the eddy is deep, currents diminish with depth (unpubl. data). Thus diel migration could lead to slower circulation around the eddy, and so affect its retention ability. Also, we have not addressed the role of the inshore coastal current known as the Southland Current extension (Heath 1975). The mean flow and variability in this current are not well known. Heath (1972b) suggests that it extends only to about Cape Turnagain (one-third of the way up the east coast of the North Island; Fig. 2), our ADCP data, however, show northward flow inshore all the way up to East Cape. Rock lobster puerulus settlement begins earlier in the year to the south along this coast (Booth 1994), so it seems likely that the current affects the transport of pueruli along the coast.

Further studies of larval recruitment off southeast New Zealand await the development of more sophisticated models of the region that will incorporate these mechanisms, include diel vertical migration, and will allow us to address such questions as how El Niño Southern Oscillation events might influence the interannual retention of larvae, and whether any exchanges of larvae between ECC and waters farther to the east are also important.

Acknowledgements. We thank E. Abraham, J. Forman, N. Oiens, D. Singleton, B. Stanton, R. Stewart, M. Walkington, and S. Wilcox for participating in the cruise and for their work in obtaining the data used here. The master and crew of $\mathrm{R} / \mathrm{V}$ 'Tangaroa' are thanked for their help in all aspects of the cruise. Without the assistance of all these people, this work could not have been accomplished. We thank L.-L. Fu for providing TOPEX/Poseidon data, and B. Cornuelle and L. Lehmann for assistance with the gridding of the data. This work was carried out under Foundation of Research, Science and Technology contract CO 1422 and Ministry of Fisheries project CRA9702.

\section{Appendix 1}

To find whether the larval stages and pueruli had different distributions, we tested whether the proportion of each catch accounted for by each group (mid-, late-, pueruli) was significantly different from uniform across each transect. That is, for each station, we calculated

$$
\begin{aligned}
& r_{1}=\sum \text { mid } / \sum(\text { mid }+ \text { late }+ \text { pueruli }) \\
& r_{2}=\sum \text { late } / \sum(\text { mid }+ \text { late }+ \text { pueruli }) \\
& r_{3}=\sum \text { pueruli } / \sum(\text { mid }+ \text { late }+ \text { pueruli })
\end{aligned}
$$

where $r_{1}+r_{2}+r_{3}=1$. Fig. 8 shows $r$ plotted as a function of distance offshore for the 5 transects.

In the first 4 transects there is a region inshore where $r_{2}$ has consecutive values greater than $I_{1}$ (i.e. there are more latestage than mid-stage phyllosomas), and a region offshore where $r_{1}$ is often greater then $r_{2}$. In the fifth transect, $r_{2}$ dominates $r_{1}$ everywhere. Overall, apart from where absolute numbers are low, it appears that the late-stage larvae dominate inshore whereas the mid-stage larvae dominate offshore. In order to provide some confidence in this statement, we did a bootstrap test to test whether the observed distribution of ratios is significantly different from that expected by random chance. This is done by computing a mean weighted position parameter for each species on $e^{\text {ach }}$ transect $\left(w_{i}=\sum_{n=1}^{N} I_{\text {in }} x_{n}\right.$ for $i=1,2,3, N=$ number of stations on each transect, $x$ is the sequence number offshore). This parameter has a low value if the ratios are skewed inshore, and high value for ratios skewed offshore. Using MonteCarlo simulations, we randomly reordered the catch ratios 10000 times, and computed $w_{1}$ each time. By computing the observed $w_{i}$ within the distribution, one can determine the likelihood that observed $w_{j}$ was obtained from an unordered distribution.

The results are shown in Fig. 8. Transects 2 and 3 show a clear picture: observed puerulus distributions (i.e. $w_{3}$ ) fall below the 5 th percentile, and mid-stage larvae fall above the 95th percentile. Late-stage larvae fall between the 25 th and 64 th percentile. We interpret this to mean that there is only a $5 \%$ or less chance that observed puerulus and mid-stage larval distributions are taken from a uniform distribution, pueruli are skewed towards the coast, and mid-stage larvae are skewed away from the coast. Late-stage larval distributions are not significantly different from uniform across the transects at the $95 \%$ level. We interpret this to mean that the late-stage larvae are found more inshore than the mid-stage larvae, but not as close inshore as the pueruli. Transects 1 and 4 show a similar picture, although the confidence limits are not so high. Transect 5 is different-here the mid-stage larvae are inshore not offshore. 


\section{LITERATURE CITED}

Annala JH, Bycroft BL (1987) Fecundity of the New Zealand red rock lobster, Jasus edwardsii. $\mathrm{N} Z \mathrm{~J}$ Mar Freshw Res $21: 591-597$

Annala JH, Sullivan KJ (1998) Report from the mid-year fisheries assessment plenary, November 1998: stock assessments and yield estimates. National Institute of Water and Atmospheric Research, Report unpublished, Wellington

Baisre JA (1994) Phyllosoma larvae and the phylogeny of Palinuroidea (Crustacea: Decapoda): a review. Aust J Mar Freshw Res 45:925-944

Booth JD (1994) Jasus edwardsii larval recruitment off the east coast of New Zealand. Crustaceana 66(3):295-317

Booth JD, Phillips BF (1994) Early life history of spiny lobster Crustaceana 66(3):271-294

Booth JD, Stewart RA (1992) Distribution of phyllosoma larvae of the red rock lobster Jasus edwardsii of the east coast of New Zealand in relation to the oceanography. In: Hancock DA (ed) Larval biology, proceedings no. 15, Australian Society for Fish Biology Workshop: Australian Government Publishing Service, Canberra

Booth JD, Forman JS, Stotter D (1998) Abundance of early life history stages of the red rock lobster, Jasus edwardsii, with management implications. National Institute of Water and Atmospheric Research, Report 98/10, Wellington

Chiswell SM, Roemmich D (1998) The East Cape Current and two eddies: a mechanism for larval retention? NZ J Mar Freshw Res 32(3):385-397

Chiswell SM, Walkington M, Stanton BR (1993) CTD data from Tasman-WOCE 1, NZOI cruise 3008, Akademik Lavrentyev, WOCE sections PR-13N, PR-11. National Institute of Water and Atmospheric Research, Report Physics section report 93-4, Wellington

Fu LL, Christensen EJ, Yamarone CA, Lefebvre M, Menard Y, Dorrer M, Escudier P (1994) Topex/Poseidon mission overview. J Geophys Res 99:24369-24381

Heath RA (1972a) Choice of a reference surface for geostrophic currents around New Zealand. NZ J Mar Freshw Res 6(1): $148-177$

Heath RA (1972b) The southland current. NZ J Mar Freshw Res 6(4):497-533

Heath RA (1975) Oceanic circulation off the east coast of New Zealand. Memoirs of the New Zealand Oceanographic Institute 55. New Zealand Oceanographic Institute, Wellington

Jeffs A, Diebel CE, Hooker SH (1997) Arrangement and significance of pinnate sensory setae on antennae of the puerulus and post-puerulus of the spiny lobster, Jasus edwardsii (Palinuridae). Mar Freshw Res 48:681-686

Kittaka J (1994) Culture of phyllosomas of spiny lobster and

Editorial responsibility: Otto Kinne (Editor),

Oldendorf/Luhe, Germany its application to studies of larval recruitment and aquaculture. Crustaceana 66(3):258-270

Lee TN, Clarke ME, Williams E, Szmant AF, Berger T (1994) Evolution of the Torgugas Gyre and its influence on recruitment in the Florida Keys. Bull Mar Sci 54(3): $621-646$

Lesser JHR (1978) Phyllosoma larvae of Jasus edwardsi (Hutton) (Crustacea: Decapoda: Palinuridae) and their distribution off the east coast of the North Island, New Zealand. NZ J Mar Freshw Res 12(4):357-370

Lyons WG (1980) The postlarval stage of scyllaridean lobsters. Fisheries 5(4):47-49

Macmillan DL, Phillips BF, Coyne JA (1992) Further observations on the antennal receptors of rock lobsters and their possible involvement in puerulus stage navigation. Mar Behav Physiol 19:211-225

Mitchum GT (1994) Comparison of TOPEX sea surface heights and tide gauge sea levels. J Geophys Res 99(C12): 24541-24553

Nishida S, Kittaka J (1992) Integumental organs of the phyllosoma larva of the rock lobster Jasus edwardsii (Hutton). J Plankton Res 14(4):563-573

Phillips BF (1981) The circulation of the southeastern Indian Ocean and the planktonic life of the western rock lobster. Oceanogr Mar Biol Annu Rev 19:11-39

Phillips BF, Macmillan DL (1987) Antennal receptors in puerulus and postpuerulus stages of the rock lobster Panulirus cygnus (Decapoda: Palinuridae) and their potential role in puerulus navigation. $J$ Crust Bio 7(1):122-135

Phillips BF, Olsen L (1975) Swimming behaviour of the puerulus larvae of the western rock lobster. Aust J Mar Freshw Res 26:415-417

Pielke RA (1984) Mesoscale meteorological modeling. Academic Press, Ontario

Polovina JJ, Moffitt RB (1995) Spatial and temporal distribution of the phyllosoma of the spiny lobster, Panulirus marginatus, in the northwestern Hawaiian Islands. Bull Mar Sci 56(2):406-417

Pond S, Pickard GL (1978) Introductory dynamical oceanography. Pergamon Press, Oxford

Roemmich D, Sutton PJH (1998) The mean and variability of ocean circulation past northern New Zealand: determining the representativeness of hydrographic climatologies. J Geophys Res C6:13041-13054

Walkington CM, Chiswell SM (1993) CTD Observations in the subtropical convergence Chatham Rise. Physics Section, New Zealand Oceanographic Institute, Report Physics Section Report 93/1, Wellington

Warren BA (1970) General circulation of the South Pacific. In: Wooster WS (ed) Scientific exploration of the South Pacific. Scripps Institution of Oceanography, National Academy of Sciences, Washington DC

Submitted: December 9, 1998; Accepted: March 2, 1999 Proofs received from author(s): June 21, 1999 